\title{
The Structuration Approach of Anthony Giddens
}

Es Mukunda Lamsal

\section{Abstract}

Structuration Theory developed by Anthony Giddens, a British sociologist, in response to claims by post-structuralism, holds that the structures that humans find themselves in are determined for them, and volunteerism, that suggests that humans are completely free to create their lived environment. Structuration theory has a several unique nomenclature to explain the relationships that the human "agency" has with institutions or "structure". This paper explains the use of the words and relate them to relevant examples. The understanding that Structuration Theory gives us can be very useful for understanding geographic phenomenon such as the idea of the time-space continuum. Urban arenas have a very complex set of relationships between humans and their environments; housing, movement within the environment, etcetera. The paper is also focused on understanding the connections between Giddens' theory and the field of geography. The main focus of this paper is on exploring the complexities of Giddens' Structuration Theory and understanding how it is currently being implemented in societies.

Keywords: Structuration, structuralism, agency, structure

\section{Introduction}

Societies in the developed world are becoming highly advanced and have undergone various changes in their value, knowledge and physical systems. The field of Sociology has attempted to categorize such changes as a result of various entities acting upon other actors (people), institutions or classes. Sociology has only been around since the mid nineteenth century but has provoked some of the most heated debates concerning human geography. The role we play in our shared reality with the world has come under the studies of some of the most prestigious sociologists, like Karl Marx, Emile Durkheim, and Max Weber. These figures have formulated some of the most influential theories of their time and have laid the basis of discussion for contemporary theorists. The human element in the social world has taken various positions in each theory. There are several stances that those sociologists believe are either one way or the other with no middle ground 
that balances elements from both sides (i.e. macro and micro).

Anthony Giddens, the figure that is the focus in this paper, is unique in this sense because of his thoughts on the delicate relationship between structure (external forces) and agency (internal motivations) in society; or macro versus micro perspectives respectively. Giddens' thoughts have been used by some of the most well-known policy makers in the world including the United Kingdom's Prime Minister Tony Blair. The use of sociological theories in real world policies is an important aspect to study in order to understand the intricate complexities that develop in our cities.

Giddens' early work on the basis of Sociology argued that the current state of the field was overly revolutionary. There were several theorists that were trying to create an over encompassing social theory of the social world. The role of the human agent was either solely based on volunteerism, where human action was unconstrained by social forces, or that it was too deterministic, that humans are solely restricted by their social structure. He rejected both points of view because he thought that neither theory gives proper attention to the actors themselves in producing their social reality. Giddens could be said to be a theorist of the humanistic frame of thought. He believed that it was humans that act as knowledgeable objects in conjunction with the social order to change their social reality. $\mathrm{He}$ redefines the role of structure by realizing that it can be both a constraining and an enabling element for human action. As society becomes more urban, Gidden's theory can be of great assistance to policy makers and human geographers alike to understand the needs of the current and future generations.

The UN habitat organization reports that the number of people living in metropolitan areas has been rapidly increasing and is projected to be the home for more than 6 billion people worldwide or two-thirds of the human population by 2050 . The role of the city in human development is universal. Cities are well known for their abilities to promote economic trade including employment, providing a stage for civil protest and offering a healthy lifestyle for its citizens. Yet, as our cities grow and change, it is important that we do not lose sight of the unintended consequences of such a rapid immigration to urban areas. Cities in different parts of the world are not always equal in their offering of goods and services to their citizens. 


\section{Theory of Structuration}

Anthony Giddens uses a selected vocabulary to understand his theory of Structuration. The relationship between actors and social forces may not be clear immediately but in this chapter we will explain how he uses these terms in conjunction with his theory of Structuration, the different forms of structure (social forces) and how the relationship between the two can be used to understand our shared reality.

\section{a. Structuralism}

The basis of the theory of Structuration involves the identification of the relationship between the individuals and the social forces that act upon us. In Giddens' theory of Structuration he tries to balance the role that actors play with their limited choice of position in history and in the social fabric they find themselves. In his theory, Giddens proposes that people do not have entire preference of their actions and their knowledge is restricted; nonetheless, they are the elements that recreate the social structure and produces social change (Craib, 1992, pg.33).

Structuration, as with any theoretical issue, is suggested to have two significant philosophical components; Ontology and Epistemology. Ontology is the theory that suggests the existence of some phenomenon and Epistemology emphasizes the philosophical theory of knowledge, exploring a definition for a phenomenon, recognizing both its sources and establishing its limits (Cloke, 1991, pg. 95). Giddens is more interested in proving the existence of this duality between structure and agency than defining what exactly causes or reinforces its existence.

He specifies that structure and agency cannot be separated; that they are connected to one another in what Giddens has termed the 'duality of structure'. Human actors are the elements that enable creation of our society's structure by means of invented values, norms or are reinforced through social acceptance. Yet, at the same time people are constrained by our social structure. A person is unable to choose who one's parents are or what period of time one exists. Giddens describes structure in terms of what he refers to as modalities (elaborated on in the next section); as a set of rules and resources that engages human action. He explains that rules restrict actions but the resources facilitate it. Along the same lines he also distinguishes the differences between systems of interaction and structures. 
A system of interaction, he explains, exhibits structural qualities although it is not entirely a structure itself (Cloke, 1991, pg. 101).

One of the most widely used examples of a system of interaction is speech. The monologue of a speaker is understood by the audience if they understand the language (structure). Languages use strict guidelines or rules to insure that what is being expressed is understood by the interpreter, this is what Giddens compares to element of structure. It is through the use of the actor's voice and knowledge of the language (structure) that speech (system of interaction) is understood. Therefore, Structuration is the process of structures reproducing systems; the system of interaction exists as a result of the structure of the language spoken. This relationship is what Giddens refers to as the rules and resources established by structures that facilitate and reproduce social interaction.

Giddens recommend that structures (traditions, institutions, moral codes, and other sets of expectations) are universally steady, nevertheless, could be changed mainly during the unintentional consequences of action. For example, when people begin to pay no attention to the social norms, substitute them, or reproduce them in a different way.

\section{b. Types of Structure}

Giddens identifies three kinds of structures in a social system: signification, legitimation and domination. In the stratification model of structure, Giddens attempts to illustrate the links between the structure and the system of interaction ( Jacobs, 1993). The first type of structure is signification which produces meaning through organized webs of language (semantic codes, interpretive schemes and discursive practices). Drawing on the speech example referenced above, the interaction of agents through speech "can be structured because particular interpretations of reality can be signified in our language beyond the simple meaning of mere words and thoughts" (Cloke, 1991, pg. 103). In this respect Giddens is expanding the role of the actor to be able to interpret and manipulate a structured language by interpretive meanings.

The second dimension of his stratification model, legitimation, produces a moral order via naturalization of societal norms, values and standards. When individual agents interact, they exhibit consciously, subconsciously, or unconsciously meanings (Giddens refers to these as sanctions) of their 
behavior. Interacting in this manner shapes the current social norms and are weighed against the moral rules of the structure. Therefore, whether or not an action is considered legitimate in the social order is structured by this dimension of legitimation. The final element, Domination, focuses on the production of (and exercise of) power, originating from the control of resources.

Giddens identifies that forces of domination and submission exist in the delicate power relationship that Karl Marx is well known for remarking upon. Giddens, like Marx, believes that resources are the vehicles for power. However, Marx is more interested in relationship between the 'means of production' in the capitalist societies whereas Giddens' goal is to understand the power relationship as a form of interaction between the actor and the structure. In this interaction, resources can be used as a form of authority illustrated by a boss and employee relationship. Resources can also be used in the form of property such as the allocation of wealth or property.

\section{c. Agency}

The basic human acts and resulting activities can be seen as the two defining capabilities of what Gidden's terms the 'Agency'. Giddens distinguishes between acts as a separate progression of action and action as a continuous flow of involvements by different and autonomous human agents (Cloke, 1991, pg. 99). Giddens identifies that action could be stimulated by the individual who wants to investigate what he/she is doing; the selfexamination process is referred to as reflexive monitoring (Giddens, 1984, pg. 5). Gidden's model of action, as depicted in Figure 2, has three elements of action, reflexive monitoring, rationalization and motivation of action. Each element has a specific role in the overall process of action. The atmosphere we interact with is that of an individual's action which is influenced by both unintended consequences and unacknowledged conditions of their acts. The unacknowledged circumstances involve the unconscious sources of motivation, as a persistent stream of interference in the world by special agents (Cloke, 1991, pg 101). Action or the ability to act by the agency is always interacting with power. Structuration theory suggests that the agency is the fundamental element to create any sort of change. Change can be thought of as simple as movement through space to interact with a new environment, thereof changing interaction or as complex 
as voting to pass a piece of legislature that will create new laws, changing the routine of society. Through the decision to act, either consciously or not, creates changes within the agency and to the structure that one has influence on (Mestrovic, 1998, pg.182).

\section{d. Micro vs. Macro}

Structuration is essential for both micro and macro level topics. Taking the example used previously of restricted selection of one's parents. At a micro level we cannot choose our parents but have the choice to have children. The relationships we create are in constant interaction and are controlled by the individuals themselves. On the other hand, we are not capable of organizing as a society without some form of state and social organizations. At this macro level we are held together by a common pattern of survival which is structured by a set of determined standards such as state laws. The two perspectives could not be separated; otherwise it will be difficult to understand them apart. This shared bond between individuals and exterior forces brings Giddens theory of Structuration together.

\section{Human Geography}

The previous two parts focused mainly on the ideas of Structuration Theory and Anthony Giddens' thoughts on the subject. Now it will try to explore how this theory is related to human geography and more specifically urban environments. Urban social forms are by far the most complex social reality and maybe the most difficult to analyze completely. For that reason, the focus will be on dominant social struggles, such as allocation of resources, municipal segmentation, etc. and understanding why Giddens believes that the single human agency is disregarded in other social theories.

a. Introductory Connections:

The main point of convergence between Giddens' theory and human geography would be the emphasis that Giddens gives to the knowledgeable human agency and their freedom in time and space. Humans are constantly in action in one sense or another; be it through monitoring of one's own or other's action, developing an understanding for such action or choosing their own course of action. Yet, as Giddens points out, day-to-day activities are not directly motivated but through reflective monitoring the individual can rationalize their actions (Giddens, 1984, p. 6). Therefore, according to Giddens, humans' routines are based on rational thought, not on the often 
hidden motivations that drive our actions. The relevance of the separation between routines and motivations can be witnessed through the capabilities possessed by humans and the unconscious results of their action. The idea of consequences of action is well outlined in Giddens own words:

"The consequences of what actors do, intentionally or unintentionally, are events which would not have happened if that actor had behaved differently, but which are not within the scope of the agent's power to have brought about (regardless of what the agent's intentions are) (Giddens, 1984, pg.11)."

Giddens is telling us that our current state of affairs in this world is in control of the factors that influence them, not solely restricted by our structure. This idea can be applied in several ways and at different levels of society (city v. world policy) or through institutions such as the student-teacher relationship. The way in which people have altered human development patterns can be illustrated through the application of an apartheid or racial/ ethnic segregation in city planning or the displacement of people from regions because of conflict. One of the most widely known apartheid ever to have dominated the social mainstream was in place under the South African government from 1950's until the mid-1990. South Africa, a country founded in British colonialism, created separate areas for 'white' and 'nonwhite' people to ensure European dominance in the area. Both white and non-white people were restricted by the area that they could move, do business, go to school as well as limiting who one could interact with and even marry. Racial apartheid has been used in several points throughout human history including the Native American reservations or the separate but equal standards during the black suffrage years in the United States. Today, there is no known nationally enforced apartheid mainly because the policy is considered to be a crime against humanity by the United Nations. However, it is a great example to illustrate exactly what Giddens means by the consequences of action and the result of concentrating so much power in the hands of a relatively few.

In the Structuration theory, the agency does not have complete power but is constrained by the second modality of the structure which is the societal 'rules' that limit human freedom. As said previously, structure is not completely constraining as a result of its rules but also facilitates action through resources. In many circumstances, such as South African example, resources are unevenly distributed. Most often people have identified class stratification as the main dividing point between the 'haves' and 'have-nots'. 
While Giddens would agree that class differences are a main determining factor in resource allocation he also thinks that the relationship between rules and resources is much more dynamic than solely reliant on class position. It is most important to note what Giddens is trying to prove here. By giving preference to the agency and explaining that structure has both rules and resources he is expressing his biggest disagreement with past structural theorist, such as Karl Marx, who have blindly given the structure the constraining characteristics without acknowledging its facilitating abilities as well. So, with this understanding it is imperative to seek how Structuration theory is facilitated and exists in the social world we are interacting with today. We would like to illustrate this in three ways: the effect of globalization, in separation of agents in space and in terms of multicultural city policy.

\section{b. Globalization and Time/Space}

Globalization has been a dominant issue ever since its first appearance on the world stage. It has been a concept that has been met with both great appreciations for its connective abilities and fiercely opposed because of its lack of intimacy. There are several angles to look at the issue of globalization from economic and political ties to its changes in the traditional social and cultural frameworks. Geographically it has influenced the social framework of the world most of us interact with, many times unknowingly. Take for example the internet encyclopedia website Wikipedia. The way people interact, gain and share knowledge has all changed in the last 20 years. The realm of an actor's impact on world affairs has vastly increased. This can be experienced by the increase in large foreign direct investment into businesses and countries with very little more than video conferencing and the click of the mouse. This example also illustrates that the space that someone really needs to physically cover has shrunk tremendously in day to day activities. This trend is mainly fueled by innovations in technologies and streamlined production processes.

Giddens' Structuration theory has been influential by giving us a notion for understanding how actors' routine behavior has influenced the structure of society and introducing ideas of time-space geography. Giddens stresses that "the concept of routinization...is vital to the theory of Structuration (Giddens, 1984, pg 60)." Globalization has been one of the most wellknown phenomena to be taking place around the world today, with only 
a couple of exceptions. The number of ways it has affected our daily routines has been enormous even if you don't agree with its externalities. The marketplace used to be the hub of personal interaction and trade, while, in modern societies the process has moved into computers and mobile phones. People are unconsciously covering virtual space and time by always being connected to a source of communication at many times of the day. The virtual space that we cover by shopping, talking, or trading (via global technology) is now dually connected to our daily activities with respect to the physical space and time we exist in. Giddens' duality of structure illustrates this separation in time and space that is very crucial to geographic studies very well.

Separation of people through space is fundamental to sociological and geographical frames of thought. In each, the socio-spatial patterning of human development is the key to understanding complex situations involving labor relations, housing selection, as well as, understanding demographic patterning. Giddens defines space in the following way: "Space is not an empty dimension along which social groupings become structured, but has to be considered in terms of its involvement in the constitution of the systems of interactions (Giddens, 1984, pg. 396)." Social groupings should be understood as elements of connectivity. The way people connect with each other is understood by Giddens as a matter that is closely linked to the network relationships between agents. It is interesting to view systems of interaction as a major determinant in creating space.

The example of segregation and exclusion of people from space that took place in South Africa is one of the more extreme cases but illustrates how Giddens framework matches up with real events. In more contemporary times segregation by class, race and ethnicity takes place but is much more transparent. In modern societies low income housing projects or gated communities tend to group people together by their relative market value. In this case, the agent is subject to the institutional capital market to determine the location of settlement based on the allocation of resources. The settlement of humans across space is limited and it would be believed that Giddens would agree.

When settlement occurs, the position of state and local civil facilities is usually well established but seems to be a process of continuous 
modification. For instance, a new landfill location is useful for all of society if demand is great enough but the fact that the development has several negative connotations is more likely to be located away from areas that have access to bargaining resources. As a result, low income groups may feel that they are being discriminated against because of a lack of resources. The point being that when agents settle they tend to connect with people that have similar shared experiences. Take public transportation for example, in many instances gets labeled as a low income mode of transportation (at least in the United States). The people that share the same bus line day-in and day-out are said to share a common bond and could be considered a system of interaction. The social grouping of people on the bus line reinforces the daily routine that exists in time and space. The relationship that actors share across any dimension, not just class, adds to the collective bargaining power of the group. The example presented here is one possible way to apply Giddens' Structuration theory to public service provisions. Elements such as land and housing costs may limit access of actors' settlement patterns but, as a result of settlement, collective bargaining can be established and used as a resource for agents with similar views, norms and values. Therefore, the collection of people in a region can indirectly manipulate the lived environment and alter the structure of their neighborhood. The issue of settlement patterns and social networks is a topic that is discussed in many government policies.

\section{Conclusion}

Giddens has presented a case for individual knowledge and choice within a structuralist theory that was partially, if not completely, blind to the influence that the agency has on the structure. The duality of structure is the essential to understand the complexities that exist in the relationship between the two elements. The position that he has taken has avoided volunteerism by confining the agency to a set of societal 'rules' and introduced the element of humanism by explaining that the knowledgeable agency can deduce from experiences their location in the structure. Giddens spends a significant amount of time to explain why agency should be used to explain the status of the structure. The freedom that an agency has in their environment is reliant on the context that the agency is observed in. Our placement in history and native language is not of our choosing but in the same sense the agency has a vital part to play in changing the structure when it comes to such things as policy changes. It is illustrated here why Giddens believes 
that the structure is a reflection of agency's power to influence their lived environment.

Structuration theory has argued against past structuralists' restricted view of the knowledgeable agent's influence on structure and as a result has been criticized for its claim. In the critical realism frame of thought, Giddens is suggesting that there is a relationship that agency shares with the structure; yet, it has a limited causal explanation for studying the dichotomy. The theory, they would argue, has no understanding of how or when agency changes are reflected in the structure. The main argument that they have raised concerns the necessities that need to occur for changes to be seen in both. When and how are changes by agency considered significant enough to change the structure?

GeoffHodgson, a British economist, raised this question as a chief argument that Giddens has been criticized about. This reservation of the relative completeness on Giddens part illustrates one of the main propositions in Giddens' theory. Past sociologists have attempted to explain social life through "empire building endeavors" or complete social theories for the world. Understanding Giddens involves reflection and monitoring of actions. That being said, Structuration theory does not try to "complicate things" by involving elements apart from the context which Giddens is trying to observe them in.

The examples that have been drawn upon here have illustrated the main contributions that Structuration theory has made to understanding the relationships that exist in the structures that we find ourselves, political, geographical, religious, etcetera. The knowledge gained from this understanding can be seen as a building block that humans can use to bring about change through social reform. In contrast to Marx, Giddens understands that structural change can be and has been achieved peacefully.

\section{References:}

Cloke, P., Philo, Ch. \& Sadler, D. (1991). Structuration Theory: Anthony Giddens and the Bringing Together of Structure and Agency, Cambridge polity press Oxford.

Craib, Ian. (1992). Anthony Gidden's structuration, Routledge a division of Routledge, Chapman and Hall Inc. 
Giddens, Anthony. (1984). The Constitution of Society, Cambridge polity press Oxford.

Held, David, Thompson, John. (1989). Social theory of modern societies Anthony Giddens and his critics, Cambridge University Press, 19

Mestrovic Stjepan G. (1998). Anthony Giddens the last modernist, Routledge London, 1998

Giddens, Anthony. (2009). Sociology, Polity press, Main street, USA.

Giddens, Anthony.(1991). The consequences of modernity, Polity press, Cambridge,UK.

Giddens, Anthony.(1991). The third way: The renewal of social democracy, Polity press, Cambridge,UK.

Moore, Kelly. (2008). Disrupting Science: Social Movements, American Scientists, and the Politics of the Military, Princeton University Press.

Putnam, Robert D. (2001). Bowling Alone: The Collapse and Revival of American Community, 1 st ed. Simon \& Schuster.

Mills, C. Wright. (2000). The Sociological Imagination, 40th ed. Oxford University Press,

Weber, Max. (1997) The Theory Of Social And Economic Organization, Free Press.

Dilthey, W. (1978), Descriptive Psychology and Historical Understanding, 1 st ed. Springer. 